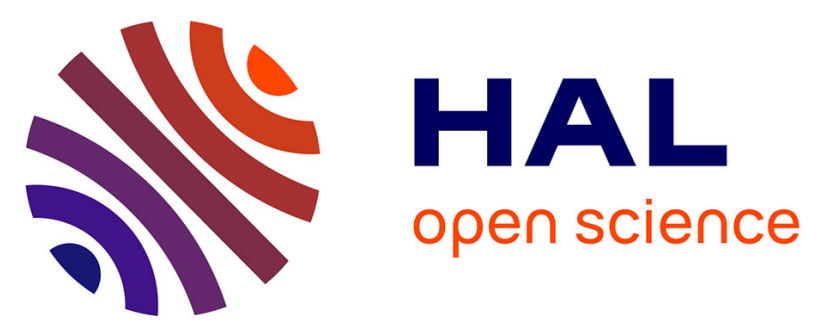

\title{
Is delayed colo-anal anastomosis an alternative to prophylactic diverting stoma after total mesorectal excision for middle and low rectal carcinomas?
}

J. Jarry, J.L. Faucheron, W. Moreno, C.A. Bellera, S. Evrard

\section{- To cite this version:}

J. Jarry, J.L. Faucheron, W. Moreno, C.A. Bellera, S. Evrard. Is delayed colo-anal anastomosis an alternative to prophylactic diverting stoma after total mesorectal excision for middle and low rectal carcinomas?. EJSO - European Journal of Surgical Oncology, 2011, 37 (2), pp.127. 10.1016/j.ejso.2010.12.008 . hal-00663075

\section{HAL Id: hal-00663075 https://hal.science/hal-00663075}

Submitted on 26 Jan 2012

HAL is a multi-disciplinary open access archive for the deposit and dissemination of scientific research documents, whether they are published or not. The documents may come from teaching and research institutions in France or abroad, or from public or private research centers.
L'archive ouverte pluridisciplinaire HAL, est destinée au dépôt et à la diffusion de documents scientifiques de niveau recherche, publiés ou non, émanant des établissements d'enseignement et de recherche français ou étrangers, des laboratoires publics ou privés. 


\section{Accepted Manuscript}

Title: Is delayed colo-anal anastomosis an alternative to prophylactic diverting stoma after total mesorectal excision for middle and low rectal carcinomas?

Authors: J. Jarry, J.L. Faucheron, W. Moreno, C.A. Bellera, S. Evrard

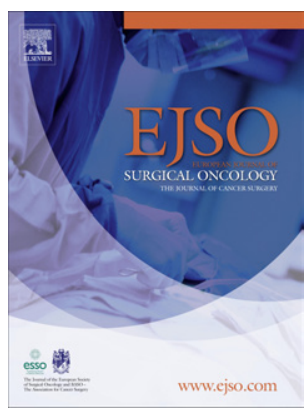

PII:

S0748-7983(10)00607-4

DOI:

10.1016/j.ejso.2010.12.008

Reference: YEJSO 3087

To appear in: European Journal of Surgical Oncology

Received Date: 31 May 2010

Revised Date: 15 October 2010

Accepted Date: 6 December 2010

Please cite this article as: Jarry J, Faucheron JL, Moreno W, Bellera CA, Evrard S. Is delayed colo-anal anastomosis an alternative to prophylactic diverting stoma after total mesorectal excision for middle and low rectal carcinomas?, European Journal of Surgical Oncology (2010), doi: 10.1016/j.ejso.2010.12.008

This is a PDF file of an unedited manuscript that has been accepted for publication. As a service to our customers we are providing this early version of the manuscript. The manuscript will undergo copyediting, typesetting, and review of the resulting proof before it is published in its final form. Please note that during the production process errors may be discovered which could affect the content, and all legal disclaimers that apply to the journal pertain. 


\title{
Original article
}

Is delayed colo-anal anastomosis an alternative to prophylactic diverting stoma after total mesorectal excision for middle and low rectal carcinomas?

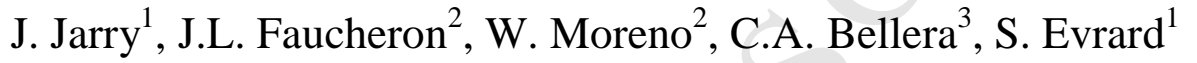 \\ ${ }^{1}$ Institut Bergonié, Université de Bordeaux, Digestive Tumor Unit, \\ 229 cours de l'Argonne, 33076 Bordeaux Cedex, France. \\ ${ }^{2}$ Hôpital Albert Michallon, Université de Grenoble, Colorectal Unit, BP 217 , \\ 38043 Grenoble Cedex 9, France \\ ${ }^{3}$ Institut Bergonié, Clinical Research and Clinical Epidemiology Unit, \\ 229 cours de l'Argonne, 33076 Bordeaux Cedex, France.
}

\section{Correspondence}

Prof S. Evrard, Digestive Tumor Unit, Institut Bergonié, 229 cours de l'Argonne, 33076 Bordeaux Cedex, France. Tel: +33 (0)5 56333266 - Fax: +33 (0)5 56333383 e-mail : evrard@bergonie.org 


\begin{abstract}
Background: After total mesorectal excision (TME), a low colorectal or colo-anal anastomosis is usually performed. A prophylactic covering stoma is often used, especially for patients receiving neoadjuvant chemo-radiotherapy. However, morbidity is high, mainly due to anastomotic leakage.
\end{abstract}

Methods: From May 2000 to October 2008, patients with middle or low rectal cancer who underwent a trans-anal pull-through procedure after TME were prospectively recorded. No covering stoma was performed in these patients. However, they all underwent a delayed colo-anal anastomosis (DCA), which was performed 6 days following the TME, on average. Both the surgical technique and follow-up were standardized. Patients with T3, $\mathrm{T} 4$ and/or $\mathrm{N}+$ cancers were given pre-operative radiotherapy. A retrospective analysis was done to assess post-operative mortality, morbidity, and oncologic and functional results.

Results: One hundred consecutive patients with rectal tumours at a median distance of 5 $\mathrm{cm}$ from the anal verge underwent DCA after TME. The 5-year overall and disease-free survival rates were $81 \%$ and $66 \%$, respectively. The post-operative mortality rate was $3 \%$ and the overall post-operative morbidity rate was $36 \%$, with only 3 anastomotic leakages. After two years, $73 \%$ of the patients had good functional outcomes.

Conclusion: The trans-anal pull-through procedure after TME, followed by DCA seems to be a safe and efficient sphincter-preserving procedure to treat patients with middle or low rectal cancer while avoiding a prophylactic, diverting stoma.

Keywords: diverting stoma, rectal cancer, delayed colo-anal anastomosis, fistula, proctectomy, total mesorectal excision 


\section{Introduction}

The surgical treatment of lower rectal cancers has evolved from abdomino-perineal resection to proctectomy with TME and colo-anal anastomosis. The main drawback of colo-anal anastomosis is the risk of leakage, which is reported to occur in $2.9 \%-20 \%$ of cases $[1,2]$. In half of these cases, the anastomotic leakage requires an additional operation [3], and a third of these require the creation of a definitive colostomy [4]. Furthermore, anastomotic leakage represents the third main cause of post-operative fatalities in rectal surgery after myocardial infarction and bronchopneumonia [5]. It also results in a higher prevalence of local, tumoral, recurrence [6]. In order to reduce the burden of the anastomotic leakage, a prophylactic covering stoma is frequently created. However, this stoma can result in minor to severe complications in $10 \%$ of cases $[7,8]$. Additionally, the construction of a stoma is generally regarded as an unfavourable outcome, since the quality of life experienced by stoma patients is considered inferior to that of non-stoma patients [9]. Finally, it imposes significant medical costs for society. In 1932, Babcock described a new technique of trans-anal colonic pull-through [10]. More recently, Baulieux [11] proposed an operative technique halfway between Babcock's pull-through and Park's direct colo-anal anastomosis [12] that is now performed routinely in our hospitals. In comparison to direct colo-anal anastomosis, this new surgical concept has a main theoretical advantage: a prophylactic stoma does not need to be performed due to the very low risk of anastomotic leakage. In this retrospective study we present the results of 100 consecutive delayed colo-anal anastomosis (DCA).

\section{Methods}

\section{Patient selection}

The trans-anal pull-through procedure followed by a DCA was the standardised operation for patients with middle and low rectal cancer in two French university medical centres 
(Grenoble Hospital and the Regional Cancer Centre Bergonié in Bordeaux). A patient database was compiled prospectively within the two institutions. The preoperative assessment included a digital rectal examination, a colonoscopy with biopsy, a CT scan of the thorax, abdomen and pelvis and a pelvic MRI. The precise level of the lower edge of the tumour from the anal verge was assessed by the surgeon. Patients were classified according to the UICC classification. Patients with T3, T4 and/or N+ disease received preoperative radiotherapy or chemo-radiotherapy. Surgery was performed 6 weeks on average after radiotherapy. We performed a preoperative evaluation of anal sphincter function for all patients by digital anal exploration. No patient suffered from faecal incontinence or had a hypotonic sphincter - both of which would have necessitated an abdominoperineal resection. The preoperative anaesthetic evaluation was done using the American Society of Anesthesiology guidelines. The criteria for laparoscopic approach was the presence of a tumour limited to the rectum and the mesorectum, without any extension to adjacent organs, and regardless of the distance of the lesion from the anal verge.

\section{Operative procedure}

The surgical procedure of laparoscopic TME followed by colonic pull-through and DCA involved two stages. In the first stage, the patient was placed in a Lloyd-Davies position and an abdominoperineal approach was used. This stage was performed laparoscopically, unless there were criteria for open surgery. The surgical procedure began with the division of the inferior mesenteric vessels. The splenic flexure was then systematically detached and the left colon completely mobilized. A laparoscopic TME was performed until the pelvic floor was reached.

We then began a perineal phase. An anal retractor was used to facilitate the exposure of the anal canal. After infiltrating the sub-mucosal plane of the upper anal canal with a saline 
and adrenaline solution, a circumferential incision of the mucosa was performed at the level of the dentate line. This was followed by a short mucosectomy. The rectum was then dissected along the perineal plane until the level of the abdominal dissection was reached. The rectum and sigmoid colon were then pulled through the anal canal and cut at the level of the ligation of the inferior mesenteric artery. A colonic segment of about $10 \mathrm{~cm}$ was left outside the anal canal and tied by two stitches to the right buttock (Figures 1 and 2). After this perineal phase, we returned to the laparoscopic phase to insert a pelvic suction drain. Between the two stages, the vascularisation of the colonic segment was checked daily in order to detect any colonic necrosis.

The second surgical stage of operation was performed around the sixth post-operative day, under general anaesthesia with curarisation to relax the pelvic floor. The patient was placed in the lithotomy. No retractors were needed, and the adhesions between the anal canal and colon had to be conserved. After tying off the mesocolon at the level of the anal verge, the colonic pull-through segment was cut and a hand sewn, colo-anal anastomosis was performed using interrupted sutures at the dentate line level. In all 100 consecutive procedures performed, no covering stoma was necessary.

\section{Follow-up}

A standardized follow-up was completed, one month post-operatively, then every four months during the first two years, and every six months in the third through the fifth year. The follow-ups included clinical examination, CEA level determination, and CT scans of the thorax and abdomen. Patients with confirmed lymph node metastases received postoperative chemotherapy. Functional results over time were evaluated using questionnaires, independently completed by the patients during each follow-up consultation. 


\section{Endpoint assessment}

The endpoints of the study were the oncologic results, post-operative morbidity and mortality, and functional outcomes. The oncologic results included the rate of microscopic resection, local recurrence, distant metastases and survival rates. Complete microscopic resection was defined as $\mathrm{R} 0$ resection and included both distal and circumferential negative margins. Overall survival (OS) is defined as the delay between the date of surgery and date of death. Disease-free survival (DFS) is defined as the delay between the date of surgery and the date of the first post-operative diagnosis of local recurrence, distant metastases, or death. Initial post-operative morbidity results were accounted for up to 30 days postoperatively. Morbidity cases were recorded according to the classification of Dindo [14]. Functional results of the patients were evaluated using the Wexner continence score [13], and the Hida scoring system [9]. Wexner scores between 0 and 10 were defined as "very good" or "good", while scores greater than 10 were defined as "poor" or "very poor".

\section{Statistical methods}

Survival endpoints, including OS and DFS, were estimated using the Kaplan-Meier method. Quantitative continuous variables were presented using descriptive statistics including the median and extreme values. Qualitative variables were described using counts and proportions. All analyses were carried out using the SAS version 9.2 software for Windows (SAS Institute Inc., Cary, NC, USA.).

\section{Results}

Population study (Table 1)

From May 2000 to October 2008, 100 consecutive patients underwent a pull-through procedure after TME, followed by a DCA. The patient group was comprised of 70 men 
and 30 women with a median age of 64 years (range 27-83). The median distance between the inferior margin of the tumour and the anal verge was $5 \mathrm{~cm}$ (range 2-12). Using the American Society of Anaesthesiology classification system, 48 patients were classified as ASA 1, 34 as ASA 2, and 18 as ASA 3. Using the post-operative UICC staging, 16 patients were classified as stage 0 (complete histological response), 20 as stage I, 23 as stage II, 26 as stage III, 10 as stage IV and 5 could not be classified (missing data). Seventy patients received preoperative radiotherapy (the median dose applied to the pelvis was $45 \mathrm{~Gy}$ ), 18 of whom received concomitant chemotherapy (5-fluorouracil). Thirty patients did not receive neoadjuvant treatment.

\section{Operative data}

Seventy five patients underwent laparoscopy and twenty-five patients underwent open surgery. Among the laparoscopic cases, seven conversions were performed. The median time for the first operative stage was 276 minutes (range 150-450) and 21 minutes (range 10-40) for the second stage. The median interval between first and second stages was six days (range 2-10) and the median hospital stay was fifteen days (range 7-157).

\section{Oncologic results}

Resection was classified as R0 in 92 cases and R1 in 8 cases. None of the resections were classified as R2. Assessment of recurrence and survival was carried out with a median follow-up of 38.4 months (range 28.95-45.54). During the follow-up period, 20 patients presented a distant metastasis with a median delay of 10 months (range 1-24). Seven patients developed a local recurrence at a median time of 16 months (range 8-29) following surgery. Fourteen patients died during the follow-up period, of which ten deaths were attributed to the disease and four to other causes. The disease-free survival rate was $84 \%$ at 
1 year and $66 \%$ at 5 years and the overall survival was $94 \%$ at 1 year and $81 \%$ at 5 years (Figure 3).

\section{Postoperative morbidity and mortality}

The postoperative mortality rate was $3 \%$. This included two deaths due to cardiac complications on the $12^{\text {th }}$ and $25^{\text {th }}$ post-operative day and one further death on the $25^{\text {th }}$ postoperative day due to brain metastasis for patients who were asymptomatic before the surgery. A total of 40 post-operative complications (22 surgical and 18 medical) occurred in 36 patients, representing an overall early morbidity rate of $36 \%$. According to the classification of Dindo et al. [14], there were 8 grade I, 11 grade II, 8 grade IIIa, 13 grade IIIb, 0 grade IV and 3 grade V complications. Among the surgical complications (Table 2), ten patients were diagnosed with pelvic sepsis complications (six pelvic abscesses without evident fistula, one infected pelvic haematoma, two anastomotic fistulas and one rectovaginal fistula). Fourteen patients required an additional operation including three Hartmann's procedures, one temporary colostomy and three temporary ileostomies. Two patients had a necrosis of the exteriorised colonic segment after the first stage of the procedure. Late post-operative complications appeared in 18 patients, which consisted of 15 anastomotic stenoses, 2 colonic prolapses and 1 rectovaginal fistula requiring a temporary colostomy.

\section{Functional outcomes}

Of the 100 patients, 6 had no functional evaluation, either because they were not present for the follow-up or because they had a stoma at the time of the evaluation. Two patients required a definitive diverting stoma for major anal incontinence. The median Wexner score was 10 during the first post-operative year, but improved to 9 at the second postoperative year and 7.8 beyond the second post-operative year. During the first year, only 40 patients had good or fair functional results. Beyond the second post-operative year, 
functional results improved rapidly in both groups with $73 \%$ of results being good or fair (Figure 4). Analysis of the Hida scoring system reveals that during the first post-operative year, 20 patients had more than 6 stools per day while another 20 had less than 3 stools per day. After one year, only 7 had more than 6 stools per day and 50 patients had less than 3 stools per day. One third of all patients had no stools at night during the first post-operative year, which increased to over half in the second post-operative year. Additionally, 54 patients were able to wait more than 30 minutes before using the toilet during the first postoperative year, and the number of patients in this category rose to 70 after the first year. An overwhelming majority $(n=94)$ of the patients used a pad during the first post-operative year. However, 50 of these patients stated that the pads were used simply as a precautionary method. This number dropped slightly to 73 after the first post-operative year. Additionally, after one year, 75 patients had no usual stool incontinence, all reported perfect continence for gas, 73 could distinguish stools from gas, and 75 had sufficient continence to carry out a normal social life. Overall, 51 patients accepted treatment to improve bowel function and 35 followed a solid food diet after one year.

\section{Discussion}

Does delayed colo-anal anastomosis prevent anastomotic leakage after TME? If so, is it the next step up in rectal surgery?

\section{Principles of DCA}

Since 1950, only a few surveys about DCA have been published [15-21]. With fistula rates ranging from 0 to $7 \%$ and pelvic abscess rates from 2 to $7 \%$, local septic complication rates with DCA appear lower in comparison to direct colo-anal anastomosis (Table 3). Three hypotheses could explain these results. Firstly, at the end of the first surgical stage, the pulled-through colon is free from attachment in the anal sphincter. Consequently, the pelvic floor rises up after the effects of the curarisation disappear, and there is no 
anastomotic tension (as opposed to a direct colonal anastamosis). Secondly, before the DCA is performed, the pulled-through colon and the anal canal have already started to circumferentially adhere together. This adhesion limits the risk of potential fistulae. Thirdly, the risk of anastomotic leakage due to early necrosis of the descending colon by vascular occlusion of the Riolan's arcade is theoretically lower. This is largely due to the fact that the colonic pulled-through segment is inspected daily, therefore resulting in a quicker diagnosis of necrosis. Thus, the patient can be re-operated immediately before the 6th post-operative day, creating an opportunity for the surgeon to remove the necrotic colon and to perform a new procedure by pulling the transverse colon through the anal canal followed by a DCA. By doing so, the patient avoids a Hartmann's procedure. It is important not to confuse between necrosis of the descending colon and necrosis limited to the exterior segment only. Differential diagnosis is made by rectoscopy. Although rare (only two cases in our series), necrosis of the exterior colon may appear in patients with tight sphincters. However this is of little consequence since it will be removed during the second stage of the procedure.

\section{Theoretical advantages}

Although a DCA could be done either by open surgery or via laparoscopy, we prefer to employ the latter since it offers a better vision of the pelvis. This allows us to better visualize the hypogastric and pelvic plexuses which must be avoided during the operation. Laparoscopy also reduces the risk of developing long-term incisional hernias, which are associated with open surgery [26]. Furthermore, we do not perform an abdominal incision to remove the colo-rectal segment, which is instead pulled through the anal canal [27]. Consequently, the first stage of our operative procedure is shorter than a laparoscopic proctectomy with TME followed by direct colo-anal anastomosis since neither a covering stoma nor a colonic reservoir is needed. In comparison with open surgery, post-operative 
recovery is therefore quicker, less stressful since there is neither a stoma nor an abdominal incision (except the port incisions), and, due to lower pain levels, has reduced analgesia requirements. Furthermore, bowel function returns earlier, allowing patients to drink water on the first post-operative evening and to stand up on the second day in accordance with fast-track surgery procedures [28]. Although the median time of hospitalization following our procedure appears long (15 days), it is important to keep in mind that the direct coloanal anastomosis requires an additional hospitalization stay to close the stoma. These two hospitalizations generally amount to a longer overall hospital stay than DCA. From an oncological point of view, there is increasing evidence that laparoscopy provides equivalent oncologic results to open surgery for rectal cancer [29-31].

The main advantage of DCA is the avoidance of a covering stoma, thereby significantly improving the patient's quality of life. From a financial point of view, it should also reduce the costs of rectal cancer surgical management since there is no need for stapler devices, no stoma pouches, no nurses required to attend to the stoma, and no subsequent operations to close the temporary stoma. A financial comparative study between delayed and direct coloanal anastomosis after TME should be done to confirm this hypothesis.

\section{Theoretical functional drawbacks}

The main criticism of the DCA procedure surrounds the poor functional outcomes due to the absence of a colonic reservoir. A frequent result of direct colo-anal anastomosis is fractionation of the patient's stools as well as an increase in the degree of urgency. Consequently, some surgeons opt for a J-shaped colonic reservoir, which typically has better short-term functional outcomes $[32,33]$. While the addition of a reservoir does not improve continence, it does reduce frequency and urgency of stools [34-36], and this starting as soon as the first post-operative year [37]. Nonetheless, these functional advantages seem to diminish over time. Indeed, all studies of straight colo-anal 
anastomosis show improving functional outcomes after the first year, presumably because of an acquired compliance of the neorectum. Heriot et al.'s meta-analysis confirms these findings by demonstrating that at 2 years post-operatively, the difference in stools between straight and J-pouch colo-anal anastomosis is only 0.74 stools per day [38]. [38]. We observe similar results in our current study with $73 \%$ of good functional outcomes after two years. Recently, Remzi et al. reported similar results based on 44 DCA and concluded that functional outcomes were comparable between delayed and direct hand-sewn coloanal anastomosis groups [21]. Moreover, constructing a reservoir requires a longer operative time and is not technically possible for all the patients [39]. Additionally, the Jpouch has been shown to increase the difficulty for the neo-rectum to empty [24]. Recently, Lange et al. [40] argued that post-operative incontinence after TME occurred due to intra-operative injuries to the innervation of the levator ani. Thus, this main negative functionnal result seems to be independent from construction of a reservoir.

\section{Conclusion}

Should the relatively minor improvements in functional results offered by colonic reservoirs outweigh the safety and financial benefits of DCA in the management of low and middle rectal cancer? In the most complexe cases, the Cleveland Clinic Foundation's [21] recommends DCA as the appropriate procedure to use before creating a permanent stoma. Indeed this is a first step towards full recognition of DCA. We also advocate its use as a routine procedure in middle and low rectal cancer. In addition, our retrospective data has enabled us to construct a prospective, multicentric, phase 2 study, which is currently ongoing. 


\section{Aknowledgments}

We gratefully acknowledge Ms Antonia Giraud, Suzanne Gaskell and Pippa McKelvie for their help with the manuscript.

\section{References}

1. Vignali A, Fazio VW, Lavery IC, et al. Factors associated with the occurrence of leaks in stapled rectal anastomosis: a review of 1014 patients. J Am Coll Surg 1997;185:10513.

2. Hautefeuille P, Valeur P, Perniceni TH, et al. Functional and oncologic results after colo-anal anastomosis. Ann Surg 1988;207:61-5.

3. Nesbakken A, Nygaard K, Lunde OC. Outcome and late functional results after anastomosis leakage following mesorectal excision for rectal cancer. Br J Surg 2001; 88:400-4.

4. Eriksen MT, Wibe A, Norstein J, et al. Anastomotic leakage following routine mesorectal excision for rectal cancer in a national cohort of patients. Colorectal Dis 2005;7:51-57.

5. Longo WE, Virgo KS, Johnson FE, et al. Outcome after proctectomy for rectal cancer in Department of Veterans Affairs Hospitals: a report from the National Surgical Quality Improvement Program. Ann Surg 1998;228:64-70.

6. Bell SW, Walker KG, Rickard MJ, et al. Anastomotic leakage after curative anterior resection results in a higher prevalence of local recurrence. Br J Surg 2003;90:1261-6. 
7. Edwards DP, Leppington-Clarke A, Sexton R, et al. Stoma-related complications are more frequent after transverse colostomy than loop ileostomy: a prospective randomized clinical trial. Br J Surg 2001;88:360-3.

8. Law W, Chu W, Choi HK. Randomized clinical trial comparing loop ileostomy and loop transverse colostomy for faecal diversion following total mesorectal excision. Br J Surg 2002;89:704-8.

9. Hida J, Yasutomi M, Fujimoto K, et al. Functional outcomes after low anterior resection with low anastomosis for rectal cancer using the colonic J-pouch. Prospective randomized study for determination of optimum pouch size. Dis Colon Rectum 1996;39:978-80.

10. Babcock WW. Operative treatment of carcinoma of the rectosigmoid. Surg Gynecol Obst 1932;55:627-34.

11. Baulieux J, Olagne E, Ducerf C, et al. [Oncologic and functional results of resections with direct delayed colo-anal anastomosis in previously irradiated cancers of the lower rectum]. Chirurgie 1999;124:240-50.

12. Parks AG, Percy JP. Resection and sutured colo-anal anastomosis for rectal carcinoma. Br J Surg 1982;69:301-4.

13. Jorge JM, Wexner SD. Etiology and management of fecal incontinence. Dis Colon Rectum 1993;36:77-97.

14. Dindo D, Demartines N, Clavien PA. Classification of surgical complications. A new proposal with evaluation in a cohort of 6336 patients and results of a survey. Ann Surg 2004;240:205-12. 
15. Charrier J, Loygue J. Forty cases of rectal cancer treated by the Babcock method. Sem Hop 1950;26:2587-9.

16. Bacon HE. Present status of the pull-through sphincter-preserving procedure. Cancer 1971;28:196-203.

17. Maliakas S, Houdard C, Carles JF, et al. Babcock-Bacon type abdominotransanal amputation. Indications and results apropos of 50 cases. Ann Chir 1975;29:577-83.

18. Kirwan WO, Turnbull RB Jr, Fazio VW, et al. Pull-through operations with delayed anastomosis for rectal cancer. Br J Surg 1978;65:695-8.

19. Khubchandani IT, Karamchandani MC, Sheets JA, et al. The Bacon pull-through procedure. Dis Colon Rectum 1987;30:540-4.

20. Olagne E, Baulieux J, de la Roche E, et al. Functional results of delayed colo-anal anastomosis after preoperative radiotherapy for lower third rectal cancer. J Am Coll Surg 2000;191:643-649.

21. Remzi FH, El Gazzaz G, Kiran RP, et al. Outcomes following turnbull-Cutait abdominoperineal pull-through compared with colo-anal anastomosis. Br J Surg 2009; 96:424-9.

22. Lazorthes F, Gamagami R, Chiotasso P. Late clinical outcome in a randomized prospective comparison of colonic J pouch and straight colo-anal anastomosis. Br J Surg 1997;84:1449-51.

23. Benchimol D, Chazal M, Mouroux J, et al. Résultats carcinologiques et fonctionnels de l'anastomose colo-anale directe après exérèse totale du rectum pour cancer. Ann Chir 1994;48:596-603. 
24. Berger A, Tiret E, Parc R, et al. Excision of the rectum with colonic J pouch-anal anastomosis for adenocarcinoma of the low and mid rectum. World J Surg 1992; 16:470-7.

25. Rullier E, Laurent C, Bretagnol F, et al. Sphincter-saving resection for all rectal carcinomas: the end of the 2-cm distal rule. Ann Surg 2005;241:465-9.

26. Laurent C, Leblanc F, Bretagnol F, Capdepont M, Rullier E. Long-term wound advantages of the laparoscopic approach in rectal cancer. Br J Surg 2008;97:903-8.

27. Faucheron JL, Voirin D, Dupuy S, et al. [Laparoscopic proctectomy and delayed coloanal anastomosis for lower rectal cancer: 42 consecutive cases]. J Coeliochir 2008; 68:18-24.

28. Zargar-Shoshtari $\mathrm{K}$, Connolly $\mathrm{AB}$, Israel LH, et al. Fast-Track surgery may reduce complications following major colonic surgery. Dis Colon Rectum 2008;51:1633-40.

29. Jayne DG, Guillou PJ, Thorpe H, et al. Randomized Trial of laparoscopic-assisted resection of colorectal carcinoma: 3-year results of the UK MRC CLASSICC Trial Group. J Clin Oncol 2007;25:3061-68.

30. Laurent C, Leblanc F, Wütrich $\mathrm{P}$, et al. Laparoscopic versus open surgery for rectal cancer: long-term oncologic results. Ann Surg 2009;250:54-61.

31. Lujan J, Valero G, Hernandez Q, et al. Randomized clinical trial comparing laparoscopic and open surgery in patients with rectal cancer. Br J Surg 2009;96:982-9.

32. Hallböök O, Påhlman L, Krog M, et al. Randomized comparison of straight and colonic J pouch anastomosis after low anterior resection. Ann Surg 1996;224:58-65. 
33. Dennett ER, Parry BR. Misconceptions about the colonic J-pouch: what the accumulating data show. Dis Colon Rectum 1999;42:804-11.

34. Araki $\mathrm{Y}$, Isomoto $\mathrm{H}$, Tsuzi $\mathrm{Y}$, et al. Functionnal results of colonic $\mathrm{J}$ pouch anastomosis for rectal cancer. Surg Today 1999;29:597-600.

35. Dehni N, Cunningham C, Sarkis R, et al. Results of colo-anal anastomosis for rectal cancer. Hepatogastroenterology 2000;47:323-6.

36. Ho YH, Tan M, Seown Choen F. Prospective randomized controlled study of clinical function and anorectal physiology after low anterior resection: comparison of straight and colonic J pouch anastomoses. Br J Surg 1997;83:978-80.

37. Ortiz H, De Miguel M, Armenddriz P, et al. Colo-anal anastomosis: are functional results better with a pouch? Dis Colon Rectum 1995;38:375-7.

38. Heriot AG, Tekkis PP, Constantinides V, et al. Meta-analysis of colonic reservoirs versus straight colo-anal anastomosis after anterior resection. Br J Surg 2006;93:19-32.

39. Harris GJ, Lavery IJ, Fazio VW. Reasons for failure to construct the colonic J-pouch. What can be done to improve the size of the neorectal reservoir? Dis Colon Rectum 2002;45:1304-1308.

40. Lange MM, Van der Velde CJ. Faecal and urinary incontinence after multimodality treatment of rectal cancer. PLoS Med 2008;5:e202. 
Table 1. Demographic data and tumour characteristics

\begin{tabular}{|c|c|}
\hline $\operatorname{Sex}(M: F)$ & $70: 30$ \\
\hline Age * & $64[27-83]$ \\
\hline ASA 1 & 48 \\
\hline ASA 2 & 34 \\
\hline ASA 3 & 18 \\
\hline Distance tumour-anal verge $(\mathrm{cm})$ & $5[2-12]$ \\
\hline Preoperative radiotherapy & 52 \\
\hline Preoperative radiochemotherapy & 18 \\
\hline \multicolumn{2}{|l|}{ Postoperative UICC staging } \\
\hline Stage 0 & 16 \\
\hline Stage I & 20 \\
\hline Stage II & 23 \\
\hline Stage III & 26 \\
\hline Stage IV & 10 \\
\hline Missing data & 5 \\
\hline
\end{tabular}


Table 2. Surgical morbidity

(according to the classification of Dindo et al. ${ }^{14}$ )

Anastomotic fistula (IIIb)

Rectovaginal fistula (IIIb) $\quad 1$

Perianastomotic abscess (IIIa) 6

Pelvic hematoma (IIIb) 1

Colonic ischemia (IIIb) $\quad 4$

Colonic perforation (IIIb) 2

Occlusion (IIIb) 1

Evisceration (IIIb)

Necrosis of the exteriorised colonic segment (IIIa) 2

Prostatic bleeding (IIIb) 1

Perianal abscess (IIIa) $\quad 1$

$\begin{array}{ll}\text { Total } & 22\end{array}$ 
Table 3. Morbidity in direct coloanal anastomosis studies

\begin{tabular}{lccc}
\hline Authors & $\begin{array}{c}\text { Preventive } \\
\text { diverting } \\
\text { stoma }\end{array}$ & $\begin{array}{c}\text { Anastomotic leak } \\
(\%)\end{array}$ & $\begin{array}{c}\text { Pelvic abscess } \\
(\%)\end{array}$ \\
\hline Parks et al $^{11}$ & $100 \%$ & 7.9 & 10.5 \\
Lazorthes et al $^{22}$ & $100 \%$ & 4.6 & 4.6 \\
${\text { Hautefeuille et } \mathrm{al}^{2}}^{2}$ & $100 \%$ & 20 & - \\
${\text { Benchimol et } \mathrm{al}^{23}}^{23}$ & $100 \%$ & 8.5 & - \\
Berger et al $^{24}$ & $100 \%$ & 3 & 3.23 \\
${\text { Rullier et } \mathrm{al}^{25}}$ & $100 \%$ & 10 & 6 \\
Our series of ACAD & $0 \%$ & 3 & 3 \\
\hline
\end{tabular}



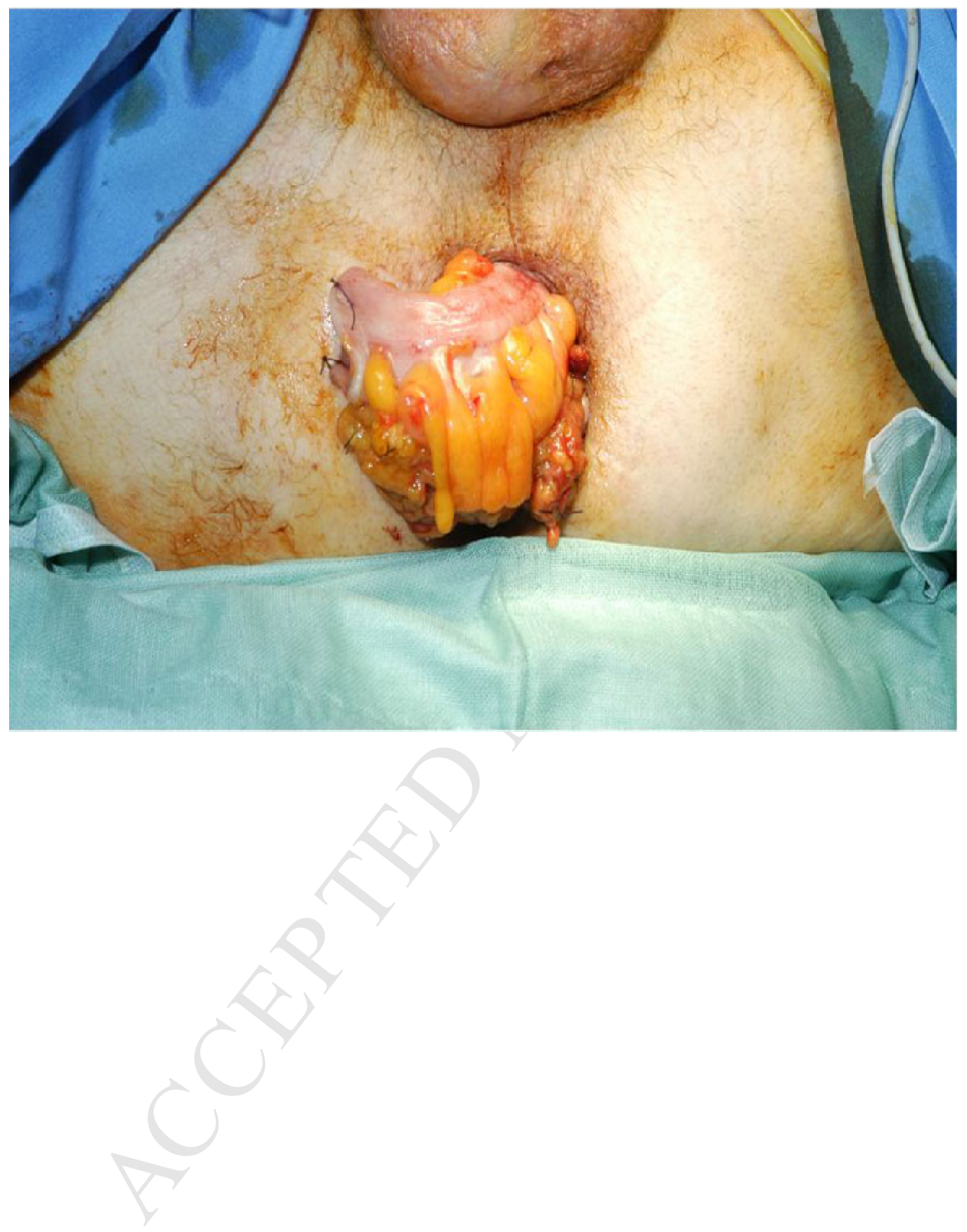


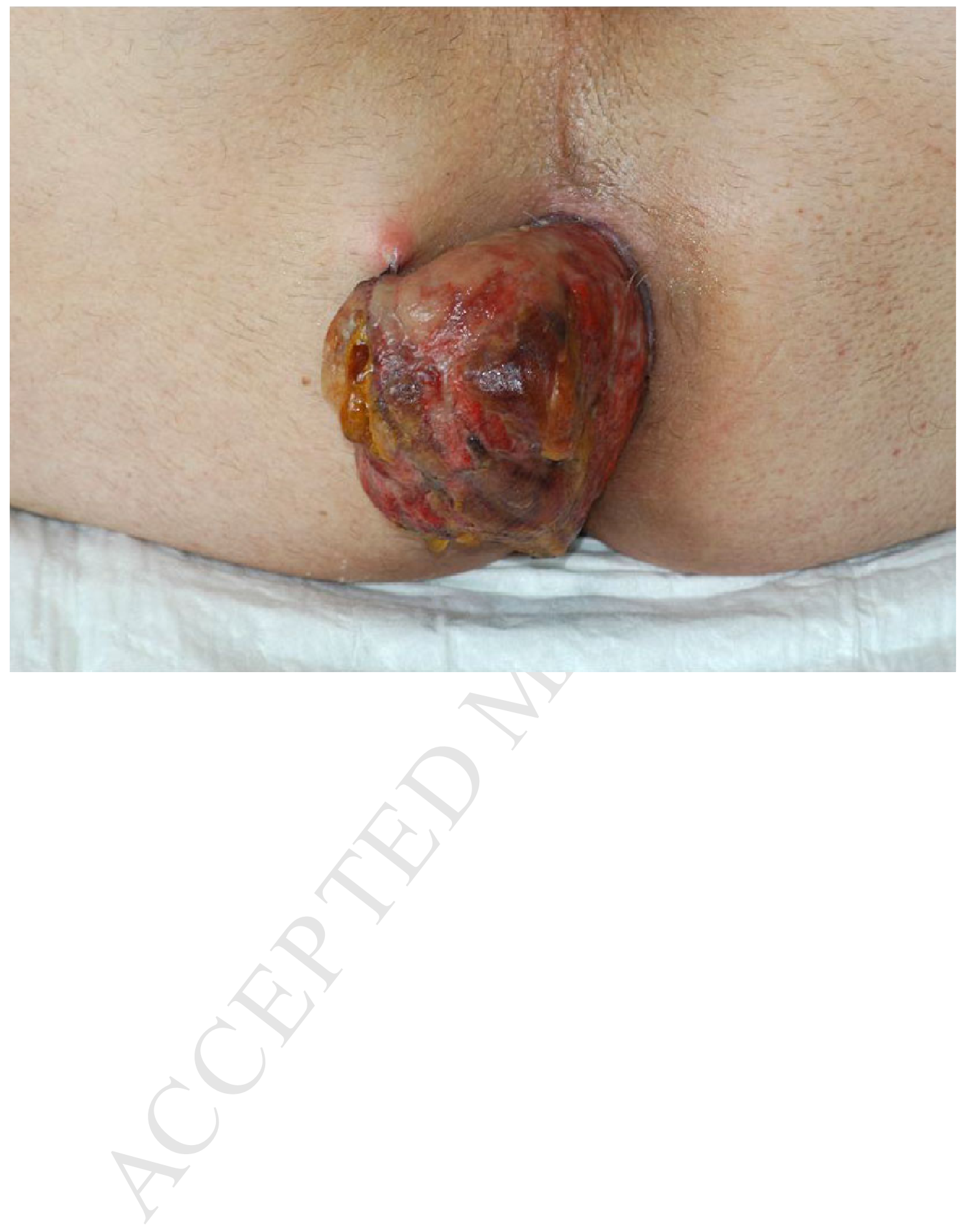




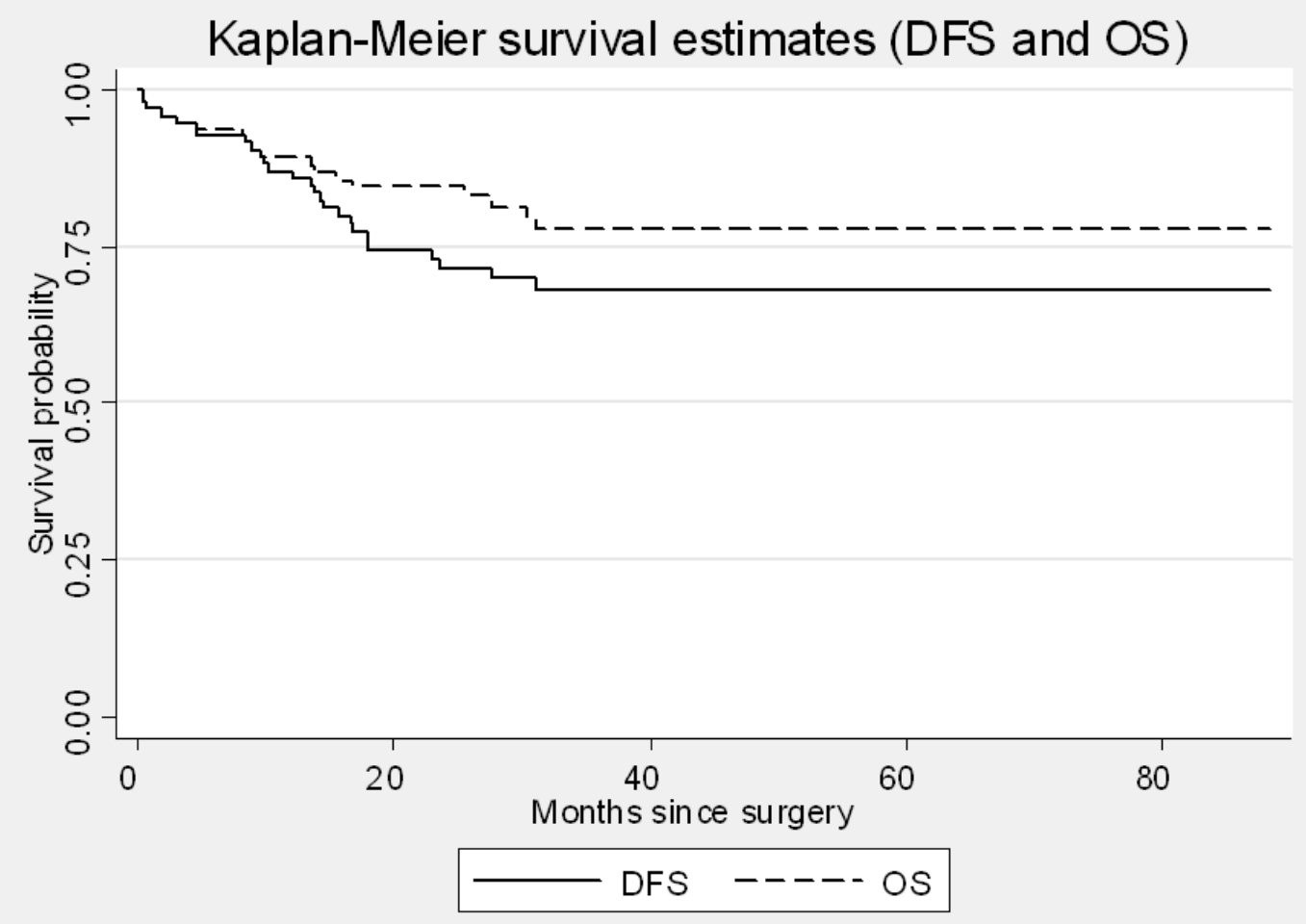




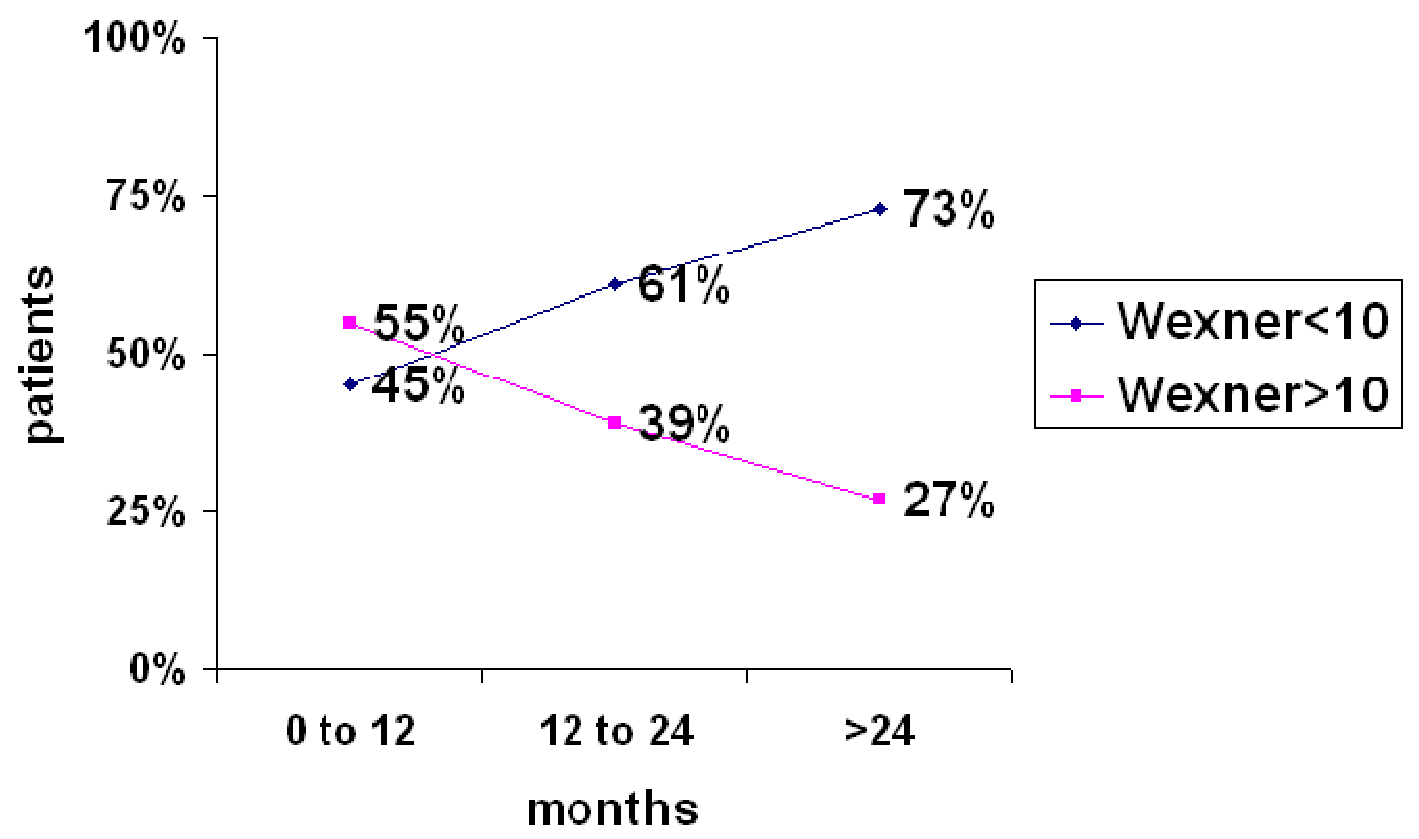

